\title{
Comparison of risk-behaviors among young people who are not in education, employment or training (NEET) versus high school students. A cross-sectional study
}

\author{
Tonje Holte Stea ${ }^{1}$, Karin de Ridder ${ }^{2}$ and Siri Håvås Haugland ${ }^{3}$ \\ 1) Faculty of Health and Sport Science, Department of Public Health, Sport and Nutrition, University of Agder, Kristiansand, Norway \\ 2) Sciensano (former Scientific Institute of Public Health), Department of Epidemiology and Public Health and Surveillance, Unit \\ Lifestyle and Chronic Diseases, Brussels, Belgium \\ 3) Faculty of Health and Sport Science, Department of Psychosocial Health, University of Agder, Kristiansand, Norway \\ Correspondence: Tonje Holte Stea, Faculty of Health and Sport, University of Agder, Service Box 422, NO-4604 Kristiansand, Norway \\ E-mail: tonje.h.stea@uia.no Telephone:+4738142324
}

\begin{abstract}
Background: Young people who are not in education, employment or training (NEET) have been identified as a vulnerable group at risk of poor social functioning, lower educational achievement, limited job opportunities and financial hardship. Being NEET has also been associated with increased risk of mental and physical health problems, but only a few studies have identified the prevalence of certain health-risk behaviors among NEET youth. The present study contributes to fill the existing knowledge gaps by investigating a broad range of risk behaviors in this vulnerable group compared to their high school peers.

Methods: This cross-sectional study included 96 NEET youth and 384 age and gender-matched high school students. A self-report questionnaire was used to assess differences in several risk behaviors, including substance use, low consumption of healthy food and high consumption of unhealthy food and beverages, low leisure time physical activity and low sleep duration. Logistic regression models were adjusted for gender, age and parental education.

Results: NEET youth had higher odds of using cannabis (OR 2.2; 95\% CI 1.1-4.3), smokeless tobacco (1.7;1.0-2.8), smoking cigarettes (2.6;1.5-4.4), having an irregular consumption of breakfast (2.6;1.5-4.5), lunch $(3.1 ; 1.8-5.4)$ and dinner (1.9;1.1-3.2), having low consumption of vegetables $(3.0 ; 1.3-6.7)$, fruit and berries (5.3;1.6-18.1) and fish (3.0;1.8-5.1) and short sleep duration on weekends $(2.6 ; 1.4-4.9)$ than students. On the other hand, being NEET was associated with decreased odds of short sleep duration on weekdays compared to their high school peers $(0.3 ; 0.2-0.5)$. No differences in alcohol intoxication, consumption frequency of evening meals, consumption of unhealthy food items and beverages and leisure time physical activity were shown between these groups.

Conclusions: NEET youth have higher odds of using tobacco, short sleep duration on weekends and lower consumption of healthy food items including vegetables, fruit and fish compared to high school students. These results contribute to identify risk behaviors that are more prevalent among NEET youth compared to students and needs to be addressed through targeted intervention studies.
\end{abstract}

This is an open access article distributed under the Creative Commons Attribution Licence, which permits unrestricted use, distribution, and reproduction in any medium, provided the original work is properly cited.

\section{BACKGROUND}

Young people who are not in education, employment or training (NEET) have been identified as a vulnerable group as NEET status is associated with numerous negative consequences, including adverse wellbeing, poor physical and mental health, difficulties entering the labour market, low earnings and social exclusion [1-3].

NEET rates vary considerably across Europe and the OECD countries $[3,4]$. In 2016, an average prevalence of $15 \%$ NEET youth was reported among 15-29-yearolds across the OECD countries, whereas a prevalence of $10 \%$ was reported among similar age groups in Norway [4]. However, the NEET group includes several sub-groups with varying degrees of vulnerability, characteristics, and needs; some have little control over their situation (unemployed, sick, disabled), while others have full control over their situation (those not seeking jobs or applying for education and not con- strained from doing so by other obligations or incapacities, and those engaged in activities such as art and travelling) [5]. Approximately 7\% of NEET youth from the EU-countries are unavailable to employment or education due to illness or disability [3]. In Norway, $11 \%$ of the young NEETs in the age of 16-21 were in 2017 classified as too sick to benefit from school or education, and in the two southern counties in Norway the proportion was $21.1 \%$ and $17.5 \%$ [6].

Previous studies have suggested that the association between NEET status and poor health may partly be explained by increased participation in health-risk behaviours, but authors have also underlined that the quality of current evidence is limited and some of the results are inconclusive [7,8]. Despite limited evidence of increased participation in a broad range of healthrisk behaviours among NEET youth, lifestyle factors that have specifically been associated with being NEET are cannabis use and smoking cigarettes [8-11]. 
Studies of American and British adolescents and young adults (aged 16-24 years old) have also shown that those disconnected from traditional employment and work settings were more likely to be in physical fights, and to use marijuana than their in-school counterparts [12], and that NEETs were less likely to participate in sports and more likely to have an unhealthy BMI than non-NEETs [8]. Studies investigating the association between alcohol use and NEET status, however, have shown inconclusive results $[2,9]$.

While the literature on NEET and lifestyle risk factors is scarce, the literature on the association between low educational attainment and/or school dropout and tobacco use, illicit drug use, insufficient sleep, low physical activity and dietary patterns is more extensive [13-16]. A systematic review reported that lower levels of education were strongly related to more risky clusters of health-related behaviour including diet, smoking, alcohol and physical inactivity [17]. Similarly, these lifestyle health behaviours cluster in adults and their prevalence is the highest among unemployed, low-educated persons and those who experience health deterioration [18].

Studies have confirmed that both physical and psychological health dimensions are associated with a higher risk for school dropout and receipt of social security benefits $[19,20]$. Identifying controllable precursors of illness and reduced health among NEET youth is therefore important in public health perspective, to avoid exclusion and preservation in a marginalized situation. Thus, the aim of the present study was to investigate differences in health-related behaviors between young people who are not in education, employment or training (NEET) and high school students in Norway.

\section{METHODS}

\section{Design and participants}

This study is based on data from two cross-sectional studies; The HELLAS study (Norwegian acronym for health, lifestyle and living conditions among NEET youth) and the Young Data Study (Ungdata). Both studies collected data during the spring 2016 in two counties (Aust- and Vest-Agder) in the Southern region of Norway, and questionnaires contained several comparable questions on background variables and lifestyle habits. Participation was voluntary, and for adolescents under the age of 16 , parents were informed and given the opportunity to reserve the youth from participation. Data was collected online, and the survey took 20-45 minutes to complete.

This study protocol was approved by the South-East Regional Committee for Medical Research Ethics (case number 2015/2431).

\section{The HELLAS study}

In Norway, the county administration is responsible for the high school services and offer follow-up services for students who do not apply for high school or quit school before completion. All NEETs between 1621 years old are registered at these services, and further categorized into various subgroups that allows for the targeting of interventions aimed for the more vulnerable groups. This also facilitated data collection among a more specific NEET-group consisting of vulnerable NEET youth at risk of marginalization [3]. In 2016, follow-up services in the southern region of Norway had registered 685 NEET youth aged 16-21, categorized as a target group (vulnerable to marginalization). During the period from March 2016 to June 2016, data was collected by inviting NEET youth, that was in contact with follow-up services for other reasons, to participate in the study. In addition, the target group received letters with information and an invitation to participate. In the largest municipality, some youthcontacts in the labor welfare system and community workers also assisted the data collection. A total of 105 respondents were included during the data collection period.

\section{The Young Data Study in Agder}

The Young Data Study in Agder included adolescents within all junior high schools (13-16 years old) and first-year students in high school (16-17 years old) from all 30 municipalities in the Southern region in Norway (for more information on Young Data, see ungdata.no). In addition, a strategic sample of 500 respondents from second and third year of high school (17-19 years old) within the same region were included. A total of 15651 students were invited to participate during school hours, and $90 \%$ of the junior high school students $(n=11042)$ and $80 \%$ of the high school students $(n=4609)$ participated.

This current study only includes data from high school students, but due to the disproportionate number of first year students in high school invited to participate versus second- and third-year students in Young Data, individual matching was applied to balance the sample. Increasing the number of controls up to a ratio of about 4/1 has been found to improve the power of a study [21]. We were able to match 96 cases from the HELLAS study with 384 controls from Young Data on age group and gender, resulting in a total sample size of $n=480$ (ratio case:control, 1:4). Matching was performed using the case-control matching procedure in SPSS, and matching tolerance were set to 0 . In multivariable analyses, respondents without missing on the included variables in each of the models were included.

\section{Measures}

All measures were based on self-reports.

\section{Outcome variables}

Information of adolescent intoxication was obtained by asking respondents how many times they had been intoxicated the past 12 months with five response alternatives: never, once, 2-5 times, 6-10 times, and more than 11 times. The variable was analyzed as a binary variable (any intoxication episodes vs. no intoxi- 
cation episodes/reference category).

Adolescent cannabis use was based on how many times respondents had used hashish/marihuana/cannabis the past 12 months. The variable was applied as a binary variable (any use vs. no use/reference category).

Information about adolescent smoking (tobacco) was obtained by asking respondents whether they smoke, with five response alternatives: 1. Never smoked; 2. Smoked in the past but have quit; 3. Smokes less than once a week; 4. Smokes weekly, but not every day; 5 . Smokes daily. This variable was applied as a binary variable, including current smoking (category 3-5) vs no current smoking (category 1-2 as reference category).

Adolescent use of smokeless tobacco was based on whether respondents reported use of snuff. There were five response categories: 1 . Never used smokeless tobacco; 2 . Have used smokeless tobacco in the past but have quit; 3 . Use smokeless tobacco less than once a week; 4. Use smokeless tobacco weekly, but not every day; 5. Use smokeless tobacco daily. The variable was analyzed as a binary variable including current use (category 3-5) vs no current use of smokeless tobacco (category 1-2 as reference category).

In Norway, dinner is normally consumed in the afternoon, and evening meals represents a lighter meal that is eaten later in the evening. Meal frequency was classified by how often respondents reported having breakfast, lunch, dinner and evening meals each week. Frequency was defined by four categories: 1 . Never or seldom; 2. Once a week; 3. 2-5 times per week; 4. Daily. This variable was dichotomized into having meals less than seven times a week or having meals every day (irregular meals).

Information on physical activity level was solicited by asking respondents how much time each week they were physically active to the level of getting warm and breathless (including physical education, leisure time exercise, family activities and self-organized activity). Response categories ranged from less than 1 hour to 13 or more hours and were dichotomized into less than 7 hours/week (low physical activity level) vs. 7 hours/ week or more (ref.).

Sleep duration was measured by asking how many hours respondents normally sleep during weekdays and weekends. Short sleep duration during weekdays and weekends was defined as less than 8 hours per day (low) vs. 8 hours or more per day (ref.).

Missing values varied between 1-5\% for substance use risk behavior, $3-10 \%$ for irregular meal pattern, $11-15 \%$ for low intake of healthy food items, $10-11 \%$ for high intake of unhealthy food items and beverages, $7 \%$ for low leisure time physical activity (LTPA) and between 15-16\% missing values for short sleep duration.

\section{Explanatory variable}

The explanatory variable was constituted by NEET (HELLAS-respondents) vs. high-school students (Young data, ref).

\section{Possible confounders}

Information regarding parental educational status was obtain by asking respondents whether their mother and whether their father had college/university education, with response alternatives yes/no (reference category). Adolescent gender was obtained by asking respondents whether they were male or female (ref). Age was in the HELLAS-study measured with 4 age categories; 16-17 years, 18-19 years, 20-21 years and 22 years and older. Due to few respondents in the latter category, this was merged with the age group 20-21, and labeled $\geq 20$ years. Age in the control group was measured by asking respondents how old they were in number of years. To match age categories used in the HELLASstudy, responses were categorized as follows; 16-17 years old, 18-19 years old and $\geq 20$ years old.

\section{Statistical analysis}

Differences in background characteristics (table 1) and prevalence of risk behaviors (table 2) were examined using Chi-square tests. Logistic regression analyses were used to explore possible associations between being NEET compared to being high school students and the outcome variables. All multivariable models were adjusted for gender, age and parental education. Results were reported as odds ratios (ORs) with 95\% confidence intervals (CIs). The level of statistical significance was set to $5 \%$.

\section{Results}

As a result of the matching process, NEET youth and high school students showed no gender or age differences. NEET youth, however, reported lower maternal $(p<0.001)$ and paternal education $(p=0.001)$ than high school students (table 1).

Table 2 presents the crude prevalence of risk behaviors among NEET youth and high school students. A higher number of NEET youth reported having used cannabis during the last 12 months $(\mathrm{p}=0.005)$, being a current user of smokeless tobacco $(\mathrm{p}=0.019)$, smoking cigarettes $(p<0.001)$, having irregular consumption of breakfast $(p<0.001)$, lunch $(p<0.001)$ and dinner

Table 1. Descriptive statistics of control/background variables.

\begin{tabular}{lccr}
\hline & $\begin{array}{c}\text { High school } \\
\text { students N (\%) }\end{array}$ & $\begin{array}{c}\text { Neet }^{1} \\
\text { N (\%) }\end{array}$ & p-value \\
\hline Total number of participants & 384 & 96 & \\
Gender, girls & $172(45)$ & $43(45)$ & 1.000 \\
Age groups & & & \\
$16-17$ & $68(18)$ & $17(18)$ & \\
$18-19$ & $224(58)$ & $56(58)$ & \\
$20+$ & $92(24)$ & $23(24)$ & 1.000 \\
Parental education & & & \\
Paternal education, lower & $187(54)$ & $63(73)$ & $\mathbf{0 . 0 0 1}$ \\
Maternal education, lower & $173(50)$ & $67(74)$ & $<\mathbf{0 . 0 0 1}$ \\
\hline${ }^{1}$ NEET = neither in education, employment, or training & \\
${ }^{2}$ Differences in gender, age and parental education were analyzed \\
using $\chi^{2}$ tests
\end{tabular}


Table 2. Crude differences in risk behaviors between high school students and NEET adolescents.

\begin{tabular}{lccr}
\hline Risk behaviors & High school students, N (\%) & Neet $^{1}, \mathrm{~N}(\%)$ & p-value \\
\hline Alcohol intoxication last 12 months & $209(57)$ & $53(57)$ & 0.951 \\
Cannabis use last 12 months & $39(11)$ & $20(22)$ & $\mathbf{0 . 0 0 5}$ \\
Currently use of smokeless tobacco & $104(27)$ & $38(40)$ & $\mathbf{0 . 0 1 9}$ \\
Currently smoking & $85(23)$ & $39(41)$ & $<\mathbf{0 . 0 0 1}$ \\
Irregular breakfast & $174(46)$ & $69(73)$ & $<\mathbf{0 . 0 0 1}$ \\
Irregular lunch & $144(38)$ & $66(70)$ & $<\mathbf{0 . 0 0 1}$ \\
Irregular dinner & $82(22)$ & $37(39)$ & $\mathbf{0 . 0 0 1}$ \\
Irregular evening meal & $191(56)$ & $55(58)$ & 0.787 \\
Low intake of vegetables & $231(73)$ & $83(90)$ & $\mathbf{0 . 0 0 1}$ \\
Low intake of fruits & $260(80)$ & $86(96)$ & $\mathbf{0 . 0 0 1}$ \\
Low intake of fish & $89(26)$ & $51(56)$ & $<\mathbf{0 . 0 0 1}$ \\
High intake of salty snacks & $43(13)$ & $16(18)$ & 0.236 \\
High intake of candy & $54(16)$ & $13(14)$ & 0.686 \\
High intake of sugar-sweetened beverages & $121(36)$ & $38(41)$ & 0.332 \\
High intake of energy drinks & $47(14)$ & $16(17)$ & 0.442 \\
Low leisure time physical activity & $242(69)$ & $70(74)$ & 0.334 \\
Low sleep, weekdays & $255(78)$ & $45(55)$ & $<\mathbf{0 . 0 0 1}$ \\
Low sleep, weekends & $54(17)$ & $27(33)$ & $\mathbf{0 . 0 0 1}$ \\
\hline
\end{tabular}

${ }^{1}$ NEET $=$ neither in education, employment, or training

${ }^{2}$ Differences in risk behaviors were analyzed using $\chi^{2}$ tests

Table 3. Adjusted odds ratio (OR) and $95 \%$ CI for adolescent substance use risk behavior ${ }^{\mathrm{a}}$ in relation to NEET status.

\begin{tabular}{|c|c|c|c|c|c|}
\hline & & $\begin{array}{l}\text { Alcohol, intoxication } \\
\text { OR (CI 95\%) }\end{array}$ & $\begin{array}{c}\text { Cannabis } \\
\text { OR (CI 95\%) }\end{array}$ & $\begin{array}{c}\text { Smokeless tobacco } \\
\text { OR (CI 95\%) }\end{array}$ & $\begin{array}{c}\text { Smoking } \\
\text { OR (CI 95\%) }\end{array}$ \\
\hline \multirow{3}{*}{ Exposure variables } & NEET & & & & \\
\hline & No & 1.0 & 1.0 & 1.0 & 1.0 \\
\hline & Yes & $1.3(0.7-2.1)$ & $2.2(1.1-4.3)^{*}$ & $1.7(1.0-2.8)^{*}$ & $2.6(1.5-4.4)^{* *}$ \\
\hline \multirow{5}{*}{ Control variables } & Gender, girls ${ }^{\mathrm{b}}$ & $0.8(0.6-1.3)$ & $0.4(0.2-0.9)^{*}$ & $0.8(0.5-1.2)$ & $0.5(0.3-0.8)^{* *}$ \\
\hline & Age, $16-17 \mathrm{yrs}^{\mathrm{c}}$ & $0.6(0.3-1.2)$ & $0.1(0.0-0.9)^{*}$ & $0.5(0.2-1.2)$ & $0.6(0.3-1.3)$ \\
\hline & Age, $18-19 \mathrm{yrs}^{\mathrm{c}}$ & $1.9(1.2-3.2)^{*}$ & $1.1(0.5-2.2)$ & $0.9(0.5-1.5)$ & $1.2(0.7-2.0)$ \\
\hline & Low paternal education ${ }^{\mathrm{d}}$ & $1.2(0.7-2.1)$ & $1.2(0.6-2.6)$ & $1.1(0.7-1.9)$ & $0.9(0.5-1.6)$ \\
\hline & Low maternal education $^{\mathrm{d}}$ & $0.5(0.3-0.8)^{* *}$ & $0.7(0.4-1.6)$ & $1.2(0.7-2.0)$ & $1.2(0.7-2.0)$ \\
\hline
\end{tabular}

${ }^{a}$ Definition: has been intoxicated during the past 12 months, has used cannabis during the past 12 months and being a current snuffer or smoker

${ }^{\mathrm{b}}$ Reference category: boys

${ }^{c}$ Reference category: age, 20-yrs

${ }^{\mathrm{d}}$ Reference category: high parental education

${ }^{*} \mathrm{p}<.05 * * \mathrm{p}<.010 * * * \mathrm{p}<.001$

$(p=0.001)$, low consumption of vegetables $(p=0.001)$, fruit/berries $(\mathrm{p}=0.001)$ and fish $(\mathrm{p}<0.001)$ and short sleep during weekends $(\mathrm{p}=0.001)$ than high school students. A higher number of high school students reported having short sleep during weekdays compared to NEET youth $(\mathrm{p}<0.001)$.

Analyses adjusted for gender, age and parental education also showed increased odds of cannabis use (OR 2.2; 95\% CI 1.1-4.3), smokeless tobacco use (1.7; $1.0-2.8)$ and smoking cigarettes (2.6;1.5-4.4) among the NEET youth compared to high school students, but no statistically significant differences in prevalence of alcohol intoxication during the last 12 months (table 3 ). Furthermore, NEET youth had increased odds of irregular consumption of breakfast $(2.6 ; 1.5-4.5)$, lunch (3.1;1.8-5.4) and dinner (1.9;1.1-3.2) compared with students (table 4). However, no differences in evening meal consumption were shown between NEETs and high school students. The results also showed that being NEET was associated with a higher odds of low intake of healthy food items, including vegetables $(3.0 ; 1.3-$ 6.7), fruit and berries (5.3;1.6-18.1) and fish $(3.0 ; 1.8$ 5.1) (table 5), whereas no differences in consumption frequency of unhealthy food and beverages (table 6) or leisure-time physical activity (table 7) were observed between the groups. Compared to their high school peers, NEET youth had increased odds of short sleep during weekends $(2.6 ; 1.4-4.9)$, but decreased odds of short sleep duration weekdays $(0.3 ; 0.2-0.5)$ (table 7$)$.

\section{Discussion}

The present study showed a higher prevalence of several health-risk behaviours among NEET youth compared to high-school students. Being NEET was associated with increased odds of cannabis use, smokeless 
Table 4. Adjusted odds ratio (OR) and $95 \%$ CI for irregular meal pattern in relation to NEET status.

\begin{tabular}{|c|c|c|c|c|c|}
\hline & & $\begin{array}{l}\text { Irregular breakfast } \\
\text { OR (CI 95\%) }\end{array}$ & $\begin{array}{l}\text { Irregular lunch } \\
\text { OR (CI 95\%) }\end{array}$ & $\begin{array}{l}\text { Irregular dinner } \\
\text { OR (CI 95\%) }\end{array}$ & $\begin{array}{c}\text { Irregular evening meal } \\
\text { OR (CI 95\%) }\end{array}$ \\
\hline \multirow{3}{*}{ Exposure variables } & High school & & & & \\
\hline & - Yes & 1.0 & 1.0 & 1.0 & 1.0 \\
\hline & - No & $2.6(1.5-4.5)^{* * *}$ & $3.1(1.8-5.4)^{* * *}$ & $1.9(1.1-3.2)^{*}$ & $1.0(0.6-1.6)$ \\
\hline \multirow{5}{*}{ Control variables } & Gender, girls ${ }^{\mathrm{b}}$ & $1.2(0.8-1.9)$ & $1.2(0.8-1.8)$ & $1.4(0.9-2.3)$ & $1.4(0.9-2.2)$ \\
\hline & Age, $16-17 \mathrm{yrs}^{\mathrm{c}}$ & $0.4(0.2-0.8)^{*}$ & $0.8(0.4-1.7)$ & $1.1(0.5-2.3)$ & $1.1(0.6-2.3)$ \\
\hline & Age, $18-19$ yrs $^{\mathrm{c}}$ & $0.8(0.5-1.4)$ & $1.4(0.8-2.3)$ & $1.0(0.6-1.8)$ & $1.0(0.6-1.6)$ \\
\hline & Low paternal education ${ }^{\mathrm{d}}$ & $2.0(1.2-3.3)^{* *}$ & $1.7(1.0-2.8)^{*}$ & $1.0(0.6-1.8)$ & $1.0(0.6-1.7)$ \\
\hline & Low maternal education ${ }^{\mathrm{d}}$ & $1.4(0.9-2.3)$ & $1.2(0.7-2.0)$ & $1.7(1.0-3.1)$ & $1.0(0.6-1.7)$ \\
\hline $\begin{array}{l}{ }^{\mathrm{a}} \text { Irregular meal pattern } \\
\mathrm{b} \text { Reference category: } \mathrm{b} \\
{ }^{\mathrm{c}} \text { Reference category: a } \\
{ }^{\mathrm{d}} \text { Reference category: } \mathrm{h} \\
*_{\mathrm{m}}<05 * * \mathrm{n}<010 * * * \mathrm{n}\end{array}$ & $\begin{array}{l}\text { is defined as having meals less } \\
\text { oys } \\
\text { ge, } 20 \text {-yrs } \\
\text { igh parental education }\end{array}$ & than seven times a weel & & & \\
\hline
\end{tabular}

Table 5. Adjusted odds ratio (OR) and $95 \%$ CI for low intake of healthy food items $\mathrm{s}^{\mathrm{a}}$ in relation to NEET status.

\begin{tabular}{|c|c|c|c|c|}
\hline & & $\begin{array}{l}\text { Low vegetables } \\
\text { OR (CI 95\%) }\end{array}$ & $\begin{array}{c}\text { Low fruits and berries } \\
\text { OR (CI 95\%) }\end{array}$ & $\begin{array}{c}\text { Low fish } \\
\text { OR (CI 95\%) }\end{array}$ \\
\hline \multirow{3}{*}{ Exposure variables } & High school & & & \\
\hline & - Yes & 1.0 & 1.0 & 1.0 \\
\hline & - No & $3.0(1.3-6.7)^{* *}$ & $5.3(1.6-18.1)^{* *}$ & $3.0(1.8-5.1)^{* * *}$ \\
\hline \multirow{5}{*}{ Control variables } & Gender, girls ${ }^{\mathrm{b}}$ & $0.4(0.2-0.7)^{* *}$ & $0.3(0.1-0.5)^{* * *}$ & $0.8(0.5-1.2)$ \\
\hline & Age, $16-17 \mathrm{yrs}^{\mathrm{c}}$ & $0.6(0.3-1.3)$ & $1.2(0.5-2.8)$ & $1.0(0.5-2.1)$ \\
\hline & Age, $18-19 \mathrm{yrs}^{\mathrm{c}}$ & $1.0(0.5-2.0)$ & $2.0(0.9-4.3)$ & $1.1(0.6-1.8)$ \\
\hline & Low paternal education ${ }^{\mathrm{d}}$ & $1.4(0.7-2.6)$ & $1.3(0.6-2.7)$ & $1.3(0.7-2.3)$ \\
\hline & Low maternal education ${ }^{\mathrm{d}}$ & $1.2(0.6-2.2)$ & $1.3(0.6-2.8)$ & $1.2(0.7-2.1)$ \\
\hline
\end{tabular}

Table 6. Adjusted odds ratio (OR) and $95 \% \mathrm{CI}$ for high intake of unhealthy food items and beverages ${ }^{\mathrm{a}}$ in relation to NEET status.

\begin{tabular}{|c|c|c|c|c|c|}
\hline & & $\begin{array}{l}\text { High salty snacks } \\
\text { OR (CI 95\%) }\end{array}$ & $\begin{array}{c}\text { High candy } \\
\text { OR (CI 95\%) }\end{array}$ & $\begin{array}{c}\text { High sugar- } \\
\text { sweetened beverages } \\
\text { OR (CI 95\%) }\end{array}$ & $\begin{array}{l}\text { High energy drinks } \\
\text { OR (CI 95\%) }\end{array}$ \\
\hline \multirow{3}{*}{ Exposure variables } & High school & & & & \\
\hline & - Yes & 1.0 & 1.0 & 1.0 & 1.0 \\
\hline & - No & $1.4(0.7-2.9)$ & $0.9(0.5-1.9)$ & $1.1(0.7-1.9)$ & $1.3(0.7-2.6)$ \\
\hline \multirow{5}{*}{ Control variables } & Gender, girls ${ }^{\mathrm{b}}$ & $2.4(1.2-4.5)^{* *}$ & $2.4(1.3-4.3)^{* *}$ & $0.9(0.5-1.3)$ & $0.7(0.4-1.3)$ \\
\hline & Age, $16-17 \mathrm{yrs}^{\mathrm{c}}$ & $0.5(1.2-1.6)$ & $0.5(0.2-1.4)$ & $0.7(0.4-1.5)$ & $0.5(0.2-1.5)$ \\
\hline & Age, $18-19 \mathrm{yrs}^{\mathrm{c}}$ & $1.1(0.5-2.5)$ & $1.5(0.7-3.0)$ & $1.2(0.7-2.0)$ & $0.9(0.5-1.8)$ \\
\hline & Low paternal education ${ }^{\mathrm{d}}$ & $1.3(0.6-2.9)$ & $0.5(0.2-1.0)^{*}$ & $0.6(0.4-1.0)$ & $1.2(0.6-2.5)$ \\
\hline & Low maternal education $^{\mathrm{d}}$ & $1.2(0.5-2.7)$ & $1.5(0.7-3.0)$ & $1.4(0.8-2.3)$ & $1.4(0.7-2.9)$ \\
\hline
\end{tabular}

${ }^{a}$ High is defined as having salty snacks, candy sweet pastries, sugar sweetened beverages, diet beverages and energy drinks $4-6$ times a week or more often.

${ }^{\mathrm{b}}$ Reference category: boys

${ }^{\mathrm{c}}$ Reference category: age, 20-yrs

${ }^{\mathrm{d}}$ Reference category: high parental education

${ }^{*} \mathrm{p}<.05 * * \mathrm{p}<.010 * * * \mathrm{p}<.001$

tobacco use, smoking cigarettes, having irregular consumption of main meals, low consumption of healthy food items and short sleep during weekends. In addition, NEET status was associated with decreased odds of short sleep during weekdays. On the other hand, no differences in alcohol intoxication, frequency of evening meal consumption, consumption of unhealthy food items and beverages or leisure time physical activity were revealed between the groups.

In line with results from the present study, a few previously published studies have also confirmed an association between being NEET and cannabis use 
Table 7. Adjusted odds ratio (OR) and $95 \%$ CI for low leisure time physical activity (LTPA) and short sleep duration ${ }^{\mathrm{a}}$ in relation to NEET status.

\begin{tabular}{|c|c|c|c|c|}
\hline & & \multirow[b]{2}{*}{$\begin{array}{c}\text { Low LTPA } \\
\text { OR (CI 95\%) }\end{array}$} & \multicolumn{2}{|c|}{ Short sleep duration } \\
\hline & & & $\begin{array}{l}\text { Weekdays } \\
\text { OR (CI 95\%) }\end{array}$ & $\begin{array}{c}\text { Weekends } \\
\text { OR (CI 95\%) }\end{array}$ \\
\hline \multirow{3}{*}{ Exposure variables } & High school & & & \\
\hline & - Yes & 1.0 & 1.0 & 1.0 \\
\hline & - No & $0.9(0.5-1.7)$ & $0.3(0.2-0.5)^{* * *}$ & $2.6(1.4-4.9)^{* *}$ \\
\hline \multirow{5}{*}{ Control variables } & Gender, girls ${ }^{\mathrm{b}}$ & $1.8(1.1-2.9)^{*}$ & $0.8(0.4-1.3)$ & $0.9(0.5-1.6)$ \\
\hline & Age, $16-17 \mathrm{yrs}^{\mathrm{c}}$ & $0.3(0.2-0.7)^{* *}$ & $0.4(0.2-1.0)^{*}$ & $0.3(0.1-0.9)^{*}$ \\
\hline & Age, $18-19 \mathrm{yrs}^{\mathrm{c}}$ & $0.5(0.3-1.0)$ & $0.8(0.4-1.6)$ & $0.6(0.3-1.1)$ \\
\hline & Low paternal education ${ }^{\mathrm{d}}$ & $1.4(0.8-2.5)$ & $1.4(0.8-2.7)$ & $2.2(1.0-4.7)^{*}$ \\
\hline & Low maternal education ${ }^{\mathrm{d}}$ & $1.9(1.1-3.3)^{*}$ & $1.5(0.8-2.8)$ & $0.9(0.4-1.9)$ \\
\hline \multicolumn{5}{|c|}{$\begin{array}{l}\text { Low LTPA is defined as being physically active less than } 1 \text { hour per week. Low sleep duration is defined as less than } 8 \\
\text { hours of sleep. }\end{array}$} \\
\hline \multicolumn{5}{|c|}{${ }^{\mathrm{b}}$ Reference category: boys } \\
\hline \multicolumn{5}{|c|}{${ }^{\mathrm{c}}$ Reference category: age, 20 -yrs } \\
\hline \multicolumn{5}{|c|}{${ }^{\mathrm{d}}$ Reference category: high parental education } \\
\hline
\end{tabular}

$[10,11]$. A British study reported both higher rates of cannabis and alcohol dependence among eighteen years-old NEET youth compared to their non-NEET peers [2], whereas a study among young Swiss men has confirmed that NEET status was associated with increased use of cannabis, but not alcohol [9]. Similar to our findings, other studies have also confirmed that NEET youth were more likely to be current smokers and smoke cigarettes more often than non-NEETs $[2,8,9,12]$. Furthermore, our study showed increased odds of using smokeless tobacco - also known as "Scandinavian snus" - among NEET youth. Despite that "Scandinavian snus" has become the most commonly used tobacco among Norwegian youth [22] and that little difference in "snus" consumption has been observed among adults in terms of education level [23], no other study has, to the best of our knowledge, reported risk of using smokeless tobacco among NEET youth compared to their high school peers. Other studies examining substance use among adolescents have shown that adolescents' drinking habits were related to their own, but not their parents' socioeconomic position [24], and that having high academic goals, such as planning to graduate from university, was identified as a strong protective factor for cannabis, alcohol and tobacco use in adolescence [25]. A cross-sectional study has also indicated that psychosocial factors, such as the inability to control life and emotional isolation, may be plausible mediators for the relationship between unemployment and smoking in Italian adults [26]. These findings are supported by a 14-year follow-up study of graduates of compulsory school in Sweden which revealed associations between long-term unemployment and respectively poor psychological health and smoking cigarettes in young men and women [27].

In general, there is a lack of studies examining the association between NEET status and other risk beha- viors than substance use, such as irregular meal consumption, unhealthy dietary habits, low leisure time physical activity and low sleep duration.

In Norway, breakfast, lunch and dinner (which is usually consumed directly after working day, e.g. 16.00-17.00), are traditionally considered to be the main meals of the day but often, the day ends with a small evening meal. Our findings, which revealed a higher odds or irregular consumption of all main meals among NEET youth compared to high school students, may be partly explained by lack of structure to their daily lives. This hypothesis must, however, be supported by future studies.

Results from the present study also indicated that NEET youth were less likely to eat healthy food as they had significantly lower odds of consuming vegetables, fruit and berries and fish compared to students. On the other hand, no differences in consumption frequency of unhealthy food items and beverages such as salty snacks, candy, sugar-sweetened beverages and energy drinks were observed between the groups. To the best of our knowledge, no other studies have investigated meal pattern among NEET youth, but results from a recently published study indicated that being NEET was associated with a reduced consumption of fruit and vegetables [8]. Based on analyses of qualitative data, some researchers have concluded that despite understanding the principles of healthy eating, a "spiral" of interrelated social, economic and associated psychological problems, contributes to render food and health of little value and low priority among unemployed, 16-20-year-old adolescents [28].

Although our results showed no differences in leisure-time physical activity between NEETs and the students, Stewart and coworkers [8] reported that being NEET was associated with reduced participation in sport after adjustment for socio-demographic characteristics. Whitehead and coworkers [25] have also con- 
firmed that adolescents anticipating university attendance exhibited higher levels of engagement in healthprotective behaviors such as increased fruit and vegetable consumption and leisure-time vigorous exercise.

Finally, our results showed that being NEET was associated with increased odds of short sleep duration on weekends and decreased odds of short sleep duration on weekdays compared to students. As far as we know, this is also the first study investigating whether NEET youth are characterized by poor sleeping habits, and these findings may support the hypothesis that being NEET is associated with a less structured lifestyle compared to their high school peers.

Overall, results from the present study indicate that being NEET is associated with an increased number of risk behaviors. It is, however, important to recognize that NEET youth represent a heterogeneous group. The present study showed that a higher number of NEET youth had parents with low education compared to the students. Previous studies and reports have also concluded that low academic achievement, low parental support and socioeconomic status (SES), as well as living in poor neighborhoods were risk factors associated with NEET status $[2,3,29,30]$. Compared to the other countries in the Organization for Economic Cooperation and Development (OECD), the percentage of inactive NEET, unemployed NEET, poor literacy and poor numeracy among NEET is substantially lower in Norway [31]. Typically for Norwegian NEET is the high percentage living alone or with a partner, as Scandinavian youth tend to move out much earlier than in other countries. Additionally, the rates for unemployment benefits or disability benefits are substantially higher among Norwegian youth compared to the OECD mean. The duration of unemployment benefits is also much longer than the OECD mean. As such, and in line with the description of Swiss NEET youth by Baggio et al [9], Norwegian NEET youth are most likely to have a generally higher social, cultural and human capital than NEET youth living in other countries due to a comprehensive school system and the Nordic welfare model. Therefore, they might less likely be characterized by high prevalence of risky behaviors compared to NEET youth in other countries. Additional cross-country studies are necessary to increase knowledge in this field.

An important limitation of the present study is the cross-sectional design, which restricts causal inference. In addition, we acknowledge that the group of NEET youth participating in the present study may not be representative for all NEETs in other countries. Another limitation of this study was the dichotomous nature of most risk behavior indicators, but this was a result of our choice to keep the questionnaire as short and simple as possible in order to increase the recruitment of participants from this vulnerable group
(NEET youth). In contrast to the recruitment process of the high school students, we experienced the recruitment process of NEET youth was difficult and time-consuming. Only those in contact with follow-up services got a face-to face-invitation, which may have affected the representability of the NEET sample. We are also aware of the fact that time of data collection in the present study coincided with application deadline for school attendance. Thus, the least vulnerable group of NEETs with intention of returning to school was most likely under-represented. The consequence of these conditions was that NEETs in Aust- and VestAgder county were not given an equal opportunity to participate in the present study. Furthermore, the strength of associations may have been underestimated due to the restricted sample size. An important strength of this study was the partnership we established with the follow-up team in the county administration in order to recruit as many NEET youth as possible, and to secure that this vulnerable group of adolescents were taken well care of during and after study participation. The most important strength of the present study is that it contributes to fill the existing knowledge gaps concerning a broad range of risk behaviors characterizing this vulnerable group. This study therefore provides much needed knowledge in order to develop well-design interventions to reach NEET youths, prevent health problems that may follow risky lifestyle behaviors, and increase the likelihood of returning to school or employment.

\section{CONCLUSION}

This study showed an increased prevalence of riskbehaviors among NEET youth, including cannabis use, smokeless tobacco, smoking cigarettes, reduced consumption of fruit and berries, vegetables and fish, and short sleep duration on weekends, whereas a decreased prevalence of short sleep duration on weekdays was reported compared to their non-NEET peers. Risk behaviors which may increase health problems and act as additional barriers to educational - and work attainment should be identified. Thus, the present results contribute to a more detailed understanding of NEET youth's characteristics, which should be considered when planning efforts to improve their situation.

\section{ACKNOWLEDGEMENTS}

We are grateful to all of the adolescents who participated in the present study. We also thank the Norwegian Social Research (NOVA), the southern regional Drug and Alcohol Competence Center (Korus), the special advisory service for NEET youth, 'Oppfølgingstjenesten' (OT), and the participating municipalities for their contributions to the data collection. 


\section{REFERENCES}

1. Marshall K. Youth neither enrolled nor employed. In: Perspectives on Labour and Income, Component of Statistics Canada Catalogue no 75-001-X; 2012.

2. Goldman-Mellor S, Caspi A, Arseneault L, Ajala N, Ambler A, Danese A, et al. Committed to work but vulnerable: Self-perceptions and mental health in NEET 18-year-olds from a contemporary British cohort. $J$ Child Psychol Psychiatry 2016; 57(2):196-203.

3. Eurofound. Exploring the diversity of NEETs. Luxembourg: Publications Office of the European Union; 2016.

4. OECD. Education at a Glance 2017. OECD Indicators, OECD Publishing, Paris; 2017. http://dx.doi.org/10.1787/eag-2017-en.

5. Eurofound. NEETs - Young people not in employment, education or training: Characteristics, costs and policy responses in Europe. In. Luxembourg: Publications Office of the European Union, 2012.

6. The Norwegian Directorate for Education and Training. Statistics portal (Statistikkportalen).2018. https://statistikkportalen.udir.no/vgs/Pages/default.aspx. Assecced 28 Feb 2018.

7. Hammer T. Unemployment and use of drug and alcohol among young people: a longitudinal study in the general population. Br J Addict 1992; 87(11):1571-81.

8. Stewart CH, Berry P, Przulj D, Treanor C. Cancer-related health behaviours of young people not in education, employment or training ('NEET'): a cross-sectional study. BMC Cancer. 2017;17:165.

9. Baggio S, Iglesias K, Deline S, Studer J, Henchoz Y, Mohler-Kuo M, et al. Not in Education, Employment, or Training Status Among Young Swiss Men. Longitudinal Associations With Mental Health and Substance Use. J Adolesc Health 2015; 56(2):238-43.

10. Danielsson A-K, Falkstedt D, Hemmingsson T, Allebeck P, Agardh E. Cannabis use among Swedish men in adolescence and the risk of adverse life course outcomes: results from a 20 year-follow-up study. Addiction 2015;110(11):1794-1802.

11. Rodwell L, Romaniuk H, Nilsen W, Carlin JB, Lee KJ, Patton GC. Adolescent mental health and behavioural predictors of being NEET: a prospective study of young adults not in employment, education, or training. Psychol Med 2018;48(5):861-71.

12. Tandon SD, Marshall B, Templeman AJ, Sonenstein FL. Health access and status of adolescents and young adults using youth employment and training programs in an urban environment. $J$ Adolesc Health 2008; 43(1):30-7.

13. Townsend L, Flisher AJ, King G. A Systematic review of the relationship between high school dropout and substance use. Clin Child Fam Psychol Rev 2007;10(4):295-317.

14. Feldman AF, Matjasko JL. The Role of school-based extracurricular activities in adolescent development: A comprehensive review and future directions. Rev Educ Res 2005;75(2):159-210.

15. Dewald JF, Meijer AM, Oort FJ, Kerkhof GA, Bögels SM. The influence of sleep quality, sleep duration and sleepiness on school performance in children and adolescents: A meta-analytic review. Sleep Med Rev 2010; 14(3):179-89.

16. Feinstein L, Sabates R, Sorhaindo A, Rogers I, Herrick D, Northstone K, Emmett P. Dietary patterns related to attainment in school: the importance of early eating patterns. J Epidemiol Community Health 2008; 62(8):734-9.

17. Noble N, Paul C, Turon H, Oldmeadow C. Which modifiable health risk behaviours are related? A systematic review of the clustering of Smoking, Nutrition, Alcohol and Physical activity ('SNAP') health risk factors. Prev Med 2015;81:16-41.

18. Schuit AJ, van Loon AJM, Tijhuis M, Ocké MC. Clustering of Lifestyle Risk Factors in a General Adult Population. Prev Med 2002;35(3):219-24.

19. De Ridder KA, Pape K, Johnsen R, Holmen TL, Westin S, Bjørngaard JH. Adolescent Health and High School Dropout: A Prospective Cohort Study of 9000 Norwegian Adolescents (The Young-HUNT). PLoS One 2013, 8(9):e74954.

20. de Ridder K, Pape K, Krokstad S, Bjørngaard JH. Health in adolescence and subsequent receipt of social insurance benefits - The HUNT Study. Tidsskr Nor Laegeforen 2015;135(10):942-8.

21. Grimes DA, Schulz KF. Compared to what? Finding controls for case-control studies. Lancet 2005; 365(9468):1429-33.

22. Norwegian institute of public health. Smoking and snus use in Norway. In: Public Health Report. Norwegian Institute of Public Health, 2017.

23. The Norwegian Institute of Public Health. Health risks of Scandinavian snus consumption - English summary (pdf). Report November 2014. ISBN (digital): 978-82-8082-644-2. Available at www.fhi.no/en.

24. Bosque-Prous M, Kuipers MAG, Espelt A, Richter M, Rimpelä A, Perelman J, et al. Adolescent alcohol use and parental and adolescent socioeconomic position in six European cities. BMC Public Health 2017; 17(1):646. 
25. Whitehead R, Currie D, Inchley J, Currie C. Educational expectations and adolescent health behaviour: an evolutionary approach. Int J Public Health 2015;60(5):599-608.

26. De Vogli R, Santinello M. Unemployment and smoking: does psychosocial stress matter? Tob Control 2005; 14(6):389-95.

27. Reine I, Novo M, Hammarström A. Does the association between ill health and unemployment differ between young people and adults? Results from a 14-year follow-up study with a focus on psychological health and smoking. Public Health 2004;118(5):337-45.

28. Davison J, Share M, Hennessy M, Knox BS. Caught in a 'spiral'. Barriers to healthy eating and dietary health promotion needs from the perspective of unemployed young people and their service providers. Appetite 2015; 85:146-54.

29. Dorsett R, Lucchino P. Explaining patterns in the school-to-work transition: An analysis using optimal matching. Adv Life Course Res 2014;22:1-14.

30. Alfieri S, Sironi E, Marta E, Rosina A, Marzana D. Young Italian NEETs (Not in Employment, Education, or Training) and the Influence of Their Family Background. Eur J Psychol 2015;11(2):311-22.

31. OECD. Society at a glance 2016: OEXD social indicators. OECD publishing, Paris; 2016. http://dx.doi.org/10.1787/9789264261488-en. 